\title{
Effects of Intragastric and Intravenous Sodium Bicarbonate on Rate of Recovery from Post-asphyxial Acidosis in the Neonate
}

\author{
R. S. EVANS, R. E. OLVER, W. J. APPLEYARD, and C. G. H. NEWMAN \\ From St. Thomas' Hospital, London
}

Evans, R. S., Olver, R. E., Appleyard, W. J., and Newman, C. G. H. (1970). Archives of Disease in Childhood, 45, 321. Effects of intragastric and intravenous sodium bicarbonate on rate of recovery from post-asphyxial acidosis in the neonate. A trial was carried out on acidotic infants recovering from neonatal asphyxia, on the relative effects of intragastric and intravenous sodium bicarbonate on acid/base balance.

Intragastric bicarbonate caused an increased rate of correction of metabolic acidosis within 30 minutes of administration. However, the $\mathrm{PCO}_{2}$ remained higher in these patients than in the controls, so that the effect of the bicarbonate on rate of $p \mathrm{H}$ correction was negligible. The rise in $\mathrm{PCO}_{2}$ occurred despite apparently normal respiratory function.

A similar limitation of $\mathrm{pH}$ rise by a sustained rise in $\mathrm{PCO}_{2}$ was evident in the intravenously treated patients.

Treatment of metabolic acidosis in neonates with sodium bicarbonate may not produce the desired correction of $p \mathrm{H}$.

Sodium bicarbonate is widely used in the treatment of neonatal acidosis, particularly in cases of asphyxia and respiratory distress syndrome (RDS). For these purposes it is usually given by the intravenous route, either by single injection or as an infusion. Dramatic clinical and biochemical improvement may follow its use in severely asphyxiated newborn infants. Since this response might be the result of changes either of a biochemical nature, or involving the pulmonary vasculature, we decided to measure the actual effect on acid-base metabolism of currently used doses of intravenous sodium bicarbonate.

In 1967 Abraham and Brown suggested that in cases of RDS, bicarbonate given intragastrically was as effective in the correction of acidosis as bicarbonate given intravenously. We have followed up this observation with a trial of intragastric and intravenous bicarbonate given to acidotic infants recovering without complication from neonatal asphyxia. The trial was designed to show the relative rate and extent of correction achieved by the two routes.

Received 22 October 1969.

\section{Material and Methods}

Observations were carried out on newborn infants recovering from moderate to severe degrees of asphyxia as judged clinically. Infants who had required urgent alkali therapy during the resuscitation procedure were excluded from the trial. Also excluded were those infants showing any clinical evidence of impairment of pulmonary function during the recovery period, in order to minimize the possibility of inadequate oxygenation causing variations in the rate of spontaneous correction of acidosis.

Those infants qualifying for the trial were randomly allocated treatment by a system of sealed envelopes and were given intravenous bicarbonate, intragastric bicarbonate, or intragastric water.

Cases allocated to intravenous treatment were given sodium bicarbonate $1.3 \mathrm{mEq} / \mathrm{kg}$. injected over two minutes via an umbilical vein catheter. This dosage, though generally insufficient for full correction, may be safely used for emergency treatment of asphyxiated infants before acid-base measurements.

Cases allocated to intragastric treatment were given either sodium bicarbonate $2 \cdot 6 \mathrm{mEq} / \mathrm{kg}$. by nasogastric tube or, in control cases, water $4 \mathrm{ml} / \mathrm{kg}$. The intragastric contents were first aspirated, and there was no vomiting or noticeable distension. All doses were given at approximately one hour after the onset of effective 
ventilation in order to avoid the more marked and unpredictable acid-base changes which occur in the first 30 minutes (James, 1963).

$1 \mathrm{ml}$. umbilical venous blood samples for acid-base analysis were withdrawn into $2 \mathrm{ml}$. heparinized plastic syringes, and kept in iced water until estimated (within 1 hour). A separate study (Evans and Olver, to be published) has shown that samples stored in this manner showed negligible changes.

Blood samples were taken immediately before treatment, and at 10 minutes, 30 minutes, 1 hour, and 2 hours after treatment. Estimation of $\mathrm{pH}, \mathrm{PcO}_{2}$, and standard bicarbonate was carried out by standard Astrup technique (Astrup et al., 1960).

\section{Results}

In the analysis of results, infants with pretreatment $\mathrm{PCO}_{2}$ levels of greater than $45 \mathrm{~mm}$. $\mathrm{Hg}$ were excluded, in order to minimize further the effects of differences in pulmonary function. Those with mild metabolic acidosis, i.e. those with pretreatment standard bicarbonate levels over $17.5 \mathrm{mEq} / \mathrm{l}$., were also excluded.

Readings obtained on 5 cases in each treatment group were analysed. Clinical data and mean values, together with standard deviations, of acidbase parameters in the three groups immediately before treatment are shown in the Table. No significant difference between these initial readings for the three groups was found.

Changes in standard bicarbonate after treatment, expressed as a percentage of the initial values, are shown in Fig. 1. The intragastric bicarbonate group showed a greater percentage rise in standard

\section{TABLE}

Clinical Data and Initial Acid-base Status; Mean Values and Standard Deviations

\begin{tabular}{l|c|c|c}
\hline & $\begin{array}{c}\text { Control } \\
\text { Group } \\
\text { Intragastric } \\
\text { Water }\end{array}$ & $\begin{array}{c}\text { Intravenous } \\
5 \%\end{array}$ & $\begin{array}{c}\text { Intragastric } \\
\text { Bicarbonate } \\
\text { Bicarbonate }\end{array}$ \\
\hline No. of cases & 5 & 5 & 5 \\
Birthweight (g.) & 2182 & 3040 & 2694 \\
& \pm 610 & \pm 1029 & \pm 466 \\
Gestational age (wk.) & 39 & $39 \cdot 6$ & 39 \\
& $\pm 2 \cdot 4$ & $\pm 1 \cdot 8$ & $\pm 2 \cdot 4$ \\
Time from effective & & & \\
oxygenation to treat- & 51 & 61 & 67 \\
ment (min.) & \pm 15 & $\pm 19 \cdot 3$ & $\pm 9 \cdot 2$ \\
& $7 \cdot 20$ & $7 \cdot 22$ & $7 \cdot 19$ \\
Initial pH & $\pm 0 \cdot 08$ & $\pm 0 \cdot 03$ & $\pm 0 \cdot 07$ \\
Initial Pco.2 (mm. Hg) & 34 & 36 & 31 \\
& \pm 8 & \pm 8 & \pm 7 \\
Initial standard bicar- & $14 \cdot 4$ & $14 \cdot 4$ & $13 \cdot 0$ \\
bonate (mEq/l.) & $\pm 2 \cdot 0$ & $\pm 1 \cdot 3$ & $\pm 2 \cdot 0$ \\
& & & \\
\hline
\end{tabular}

bicarbonate than the control group and this difference was significant at both 30 minutes and 1 hour. There was a large rise in standard bicarbo- $\overrightarrow{\vec{F}}$ nate in the intravenous group at 10 minutes, and $\frac{\vec{\sigma}}{0}$ this rise remained significantly greater than that of $\frac{C}{0}$ the control group at 30 minutes and after $60 \mathrm{o}$ minutes after administration.

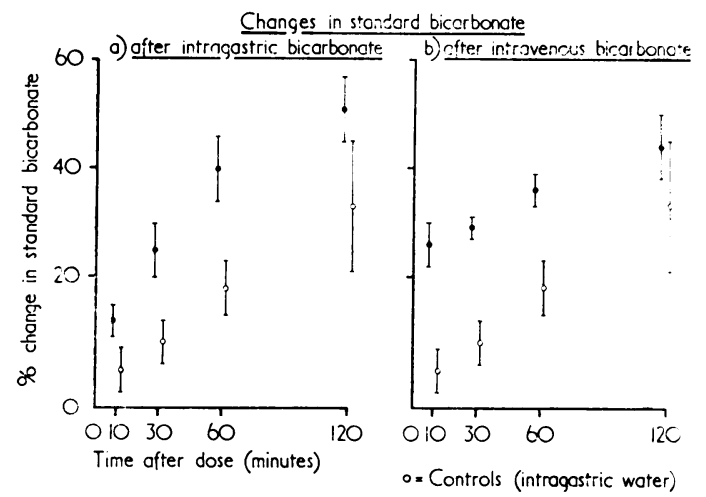

FIG. 1.-Changes in standard bicarbonate: (a) after intragastric bicarbonate; (b) after intravenous bicarbonate.

Fig. 2 shows changes in $p \mathrm{H}$ in the three groups following treatment.

It will be seen that there was little difference in rate of $p \mathrm{H}$ rise between the intragastric group and the control group, and at no stage was this difference statistically significant. The $p \mathrm{H}$ rise in the intravenous group was of only short duration.

Changes in $\mathrm{PCO}_{2}$, expressed as a percentage of initial values, are shown in Fig. 3.

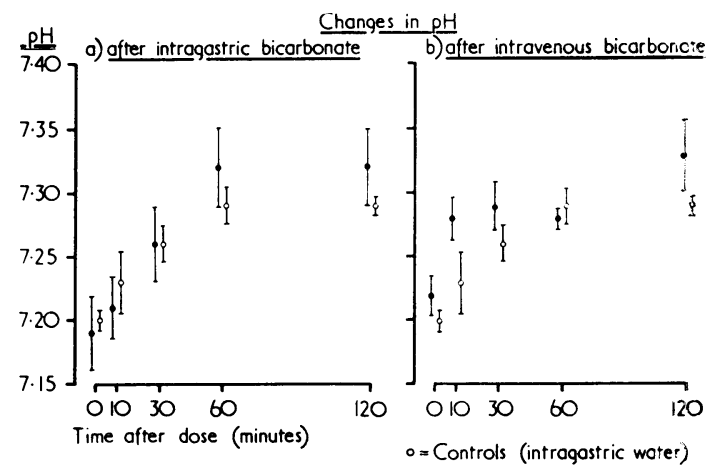

FIG. 2.-Changes in $\mathrm{pH}$ : (a) after intragastric bicarbonate; (b) after intravenous bicarbonate. 


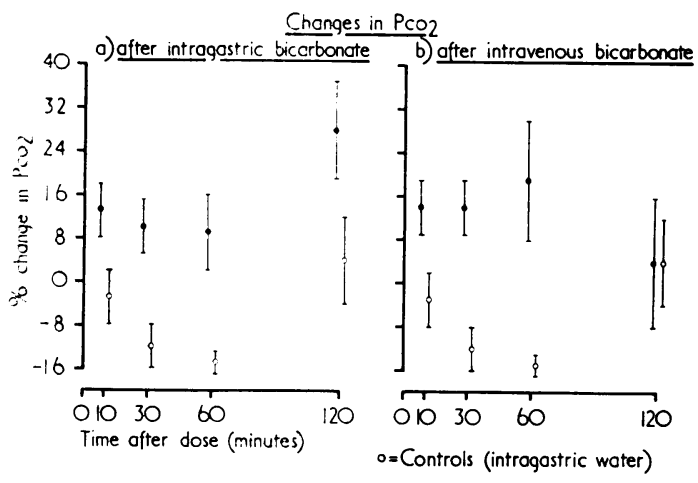

Fig. 3.-Changes in $\mathrm{PCO}_{2}$ : (a) after intragastric bicarbonate; (b) after intravenous bicarbonate.

The intragastric bicarbonate group showed a mean rise in $\mathrm{PCO}_{2}$, while in the intragastric water group the $\mathrm{PCO}_{2}$ values initially tended to fall. The difference in $\mathrm{PCO}_{2}$ between the two groups was statistically significant at 30 minutes and 1 hour, and provides an explanation of the failure of the $p \mathrm{H}$ to rise more rapidly in the intragastric bicarbonate group compared with controls, despite a more rapid rise in standard bicarbonate,

A similar phenomenon was seen after the use of intravenous bicarbonate. There was a sustained and significant rise in $\mathrm{PCO}_{2}$ values in the bicarbonate group compared with the intragastric water controls.

A comparison of the intragastric and intravenous bicarbonate groups showed a significantly greater percentage rise of $p \mathrm{H}$ at 10 minutes after intravenous injection, but the reverse (intragastric $\mathrm{pH}$ rise greater than intravenous) at 60 minutes. There was no significant difference between the two groups at 30 and at 120 minutes. At 60 minutes there was a significantly greater rise of $\mathrm{PCO}_{2}$ in the intravenous group, and the reverse at 120 minutes. The percentage rise of standard bicarbonate in the intravenous group was significantly greater at 10 minutes only; there was no significant difference subsequently. The dose of bicarbonate given into the stomach was twice that injected intravenously.

\section{Discussion}

Intragastric sodium bicarbonate has been used in the treatment of metabolic acidosis in the respiratory distress syndrome with varying reported degrees of effectiveness. Abraham and Brown (1967) found evidence that bicarbonate was well absorbed and corrected the $p H$ as effectively as bicarbonate given intravenously. Stoneman and
Owens (1968) found that though an accelerated recovery from metabolic acidosis could be achieved by giving intragastric sodium bicarbonate, there was little effect on rate of $p \mathrm{H}$ correction, for while in the untreated patient $\mathrm{CO}_{2}$ levels tended to fall, in the treated patients high $\mathrm{CO}_{2}$ levels tended to be maintained.

The results of the present study of the shortterm effects of intragastric bicarbonate administration on moderately acidotic infants tend to agree with the latter view. Though there was evidence of an increased rate of correction of metabolic acidosis within 30 minutes of treatment, the $\mathrm{PCO}_{2}$ remained higher in this group than in the controls, so that the effect on rate of correction of $p H$ was negligible. It was of interest that this effect occurred despite apparently adequate pulmonary function.

In the group treated with intravenous bicarbonate there was an immediate correction of metabolic acidosis, but the levels of $\mathrm{CO}_{2}$ again remained higher than the controls, so that the correction of $\mathrm{pH}$ achieved was rather less than might be expected. A similar effect was noted by Sinclair, Engel, and Silverman (1968) when using rapid arterial sodium bicarbonate infusion in low birthweight hypoxaemic acidaemic infants. In our series, the rise of $\mathrm{PCO}_{2}$ that modified the rise of $p \mathrm{H}$ reached its peak in the intravenous group at 60 minutes, but not until 120 minutes in the intragastric group.

In contrast, Russell and Cotton (1968) found that after injection of sodium bicarbonate into the umbilical vein of infants with early $\mathrm{RDS}$, the $\mathrm{PCO}_{2}$ tended to fall. This was attributed to improvement in pulmonary function after release of pulmonary arteriolar spasm. This may well be a mechanism responsible for the sudden improvement in some severely asphyxiated newborn infants after the use of intravenous sodium bicarbonate. Berg, Mülling, and Saling (1969) showed a rise of $\mathrm{pH}$ associated with a rise of $\mathrm{PCO}_{2}$ on injecting 1-2 mmole/kg. sodium bicarbonate into 7 rabbits, in a comparison of the effects of THAM and sodium bicarbonate. There was a considerable hyperventilatory response in the rabbits which were not, however, asphyxiated or acidotic before the injection of bicarbonate. The stimulation of respiration was probably a response to the rise in $\mathrm{PCO}_{2}$ and only indirectly attributable to the bicarbonate. The relative effects of a low $\mathrm{pH}$ and of a raised $\mathrm{PCO}_{2}$ per se are reviewed in Berg et al.'s article.

In the present state of knowledge of the indications for, and the optimal route, dose, and rate of infusion of bicarbonate, its effects are not entirely predictable. In many cases intended correction 
of the metabolic component of acidosis in the circulating blood may not be followed by the desired correction of $p \mathrm{H}$.

We thank Dr. D. G. Cottom for permission to study the infants under his care, and Professor Walter Holland for help in the design of the trial. W.J.A. received a grant from the Worshipful Company of Dyers.

\section{REFERENCES}

Abraham, J. M. and Brown, R. J. K. (1967). Comparison of intragastric and intravenous routes of glucose/bicarbonate administration in respiratory distress syndrome. British Medical fournal, 3, 640 .

Astrup, P. Jørgensen, K., Siggaard Anderson, O., and Engel, K. (1960). The acid-base metabolism. A new approach. Lancet, 1, 1035.
Berg, D., Mülling, M., and Saling, E. (1969). Use of THAM and sodium bicarbonate in correcting acidosis in asphyxiated new-․․ borns. Archives of Disease in Childhood, 44, 318

James, L. S. (1963). Perinatal acid-base balance. In Modern Trends in Human Reproductive Physiology, I, Ed. by H. M. Carey. p. 319. Butterworths, London.

Russell, G., and Cotton, E. K. (1968). Effects of sodium bicarbo- $\bar{\sigma}$ nate by rapid injection and of oxygen in high concentration in

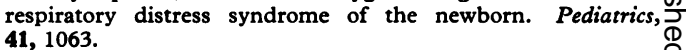

Sinclair, J. C., Engel, K., and Silverman, W. A. (1968). Early correction of hypoxemia and acidemia in infants of low birth weight: a controlled trial of oxygen breathing, rapid alkali infusion, and assisted ventilation. Pediatrics, 42, 565.

Stoneman, M. E. R., and Owens, R. M. (1968). Effects of intra- gastric sodium bicarbonate in infants with respiratory distress. $\vec{\omega}$ Archives of Disease in Childhood, 43, 155.

Correspondence to Dr. C. G. H. Newman, Westminster Hospital, Page Street, London S.W.1. 